\section{THE IMPROVEMENT OF THE RECORDS SYSTEM ON VIOLENCE AND INJURY BY APPLAYING THE RESULTS OF RESEARCH}

Budimir Šegrt, Mirjana Pešalj, Svetlana Stojanovic. Ministry of Health of Government of Montenegro, Montenegro

\subsection{6/injuryprev-2016-042156.713}

Background In 2011 in the research, Injury situation analysis for Montenegro, there are presented published data from relevant institutions reports their violence and injury evidence recording systems. From 2008 to 2015 there are done several surveys at national and global level with the aims to participate in the effective global monitoring process of evidence data system on injury and violence in accordance to the implementation of WHO Europe Regional Committee Resolution EUR/RC55/R9 on the prevention of injuries in the European Region and the Recommendation of the Council of the European Union from 2007 on the prevention of injury and promotion of safety.

Methods The surveys are done in accordance with the unique WHO methodology for delivering of Global status reports. The recording system, reporting and collecting data is the process done in accordance with the current legislative, previous established for each institutions.

Results The results of survey showed differences in numerous representations of various statistical data sets from violence and injury from different system stakeholders. Take in considerations identified deficiencies, applying multidisciplinary and multisector approach, there are done analyses, policy, strategies, action plans, legislative with the aims to establish stable, efficiency and effective reporting system at national level. The frequency of reporting and accuracy of the data are increased. Awareness about the size and importance for establishing of the efficient reporting system was raised and it is widely accepted approach of necessity of implementations of stable reporting system with the goals of effective and stable public system with evidence base approach.

Conclusions Take in considerations, survey results, relevant for injury and violence evidence system, correcting of the identified deficiencies it is reached and there are established more effective statistical reporting system on injury and violence at the national level.

\section{INTRODUCING THE CONCEPT OF WELL-BEING CAPITAL IN ENHANCING THE PRODUCTIVITY AND OCCUPATIONAL SAFETY}

'Liisa Hakala, ${ }^{2}$ Marja-Liisa Manka, ${ }^{2}$ Riitta-Liisa Larjovuori, ${ }^{2}$ Kirsi Heikkilä-Tammi. ${ }^{1}$ Ministry of Social Affairs and Health, Finland; ${ }^{2}$ University of Tampere, Finland

\subsection{6/injuryprev-2016-042156.714}

Background Because the working age population in Finland is decreasing, working careers must be extended at the beginning, in the middle and at the end of working life, unemployment must be reduced, and disabilities, absences and presenteeism due to illness and psychosocial strain must be curtailed. The overall aim defined in the Finnish strategy for social and health policy titled Socially Sustainable Finland 2020 is to lengthen working careers by an average of three years by 2020 when compared to the year 2010. The better people feel in the workplace and the more healthy they are, the longer their working careers will be and the more productive they will be. At the moment, the minimum cost of lost labour inputs, occupational accidents and diseases and health care costs are 25 billion euros a year according to calculations of Ministry of Social Affairs and Health.

Description of the problem The strategic importance of personnel well-being and work ability as human and intellectual capital of the organisation is a scarcely researched topic. In this presentation we will introduce the emerging concept of wellbeing at work capital.

Results The foundation of well-being at work capital lies in the so called extended view of intellectual capital, which includes the following: work-place social capital and leadership, structural i.e. organisational capital, knowledge capital, and psychological capital. Psychological capital refers to mental resources like self-confidence, resilience, optimism and hope.

Conclusions In addition to traditional ideas of intellectual capital, there is an increasing need for attitudinal capacities like entrepreneurship, the capacity to lead oneself and the ability to use one's own resources in a sustainable way. From the point of view of an individual, being an active participant in the modern working life requires, most of all, capacity for lifelong learning and renewal.

\section{ROAD SAFETY IS YOUR RESPONSIBILITY -WOMEN WEAR HELMET}

Harpreet Singh Dhunna. Avoid Accident India

\subsection{6/injuryprev-2016-042156.715}

Background It is disappointing to know that in $21^{\text {st }}$ century, Indian women do not wear helmets just because they are exempted and that too just because they belong to a particular religion SIKH. ${ }^{2}$ Every year, about 60 to 70 women die $^{3}$ due to head injuries sustained in road accidents involving two-wheelers in states of Northern India.

Description of problem The reason why all women (not just Sikh ones) are exempt from wearing a helmet is because it is impossible to distinguish Sikh women from other women just by looking at them. Crash helmets are unpopular among women passengers because wearing them ruins their hair styles and hampers their looks. "They find it inconvenient because of their hair. It becomes sweaty and safety is not their concern," said P.R Ullhas. ${ }^{4}$

"A woman spends a considerable time in getting a hair style done every day and also spends huge sum on hair make-up. Using a helmet will obviously spoil the efforts to look beautiful," said Jawed Habib. $^{5}$

Women usually sit sideways on a two-wheeler, which makes them more vulnerable to accidents, as there is a huge possibility of tipping over and hitting the ground even before the rider. As they do not wear helmets, they are more likely to get a head injury.

Effects So it becomes extremely important to create awareness amongst women that they should wear helmets willingly for their own safety even if it is not enforced by law.

We aim to create awareness amongst women that they should not be dependent on some traffic rule to make them wear helmets but they should willingly wear it to avoid fatal head injuries during travelling.

Union Territory of Delhi has amended the Motor Vehicle Act and made it mandatory for every women to wear the helmet.

Conclusions A woman has always exhibited diversified qualities, in the different roles that she plays in her life - as a mother, a sister, a life-partner, a friend, a daughter. So loss of a life of woman is a loss of whole society. 